\title{
Brugada Pattern Mimicking Myocardial Acute Infarct
}

Ricardo Lessa de Castro Junior ${ }^{1, *}$, Neiberg de Alcantara Lima ${ }^{1}$, Stela Sampaio Vitorino ${ }^{2}$

ORCID IDs

Castro Junior RL (DD https://orcid.org/0000-0002-8153-7998

Lima NA (D) https://orcid.org/0000-0003-3616-435X

Vitorino SS (iD https://orcid.org/0000-0003-1314-2107

\begin{abstract}
Brugada syndrome (BrS) has been described as an arrhythmic disorder characterized by ST elevation with successive negative T wave in the right precordial leads. Patients are at risk for sudden cardiac death (SCD) due to ventricular fibrillation (VF). This specific electrocardiogram (ECG) pattern can sometimes be confused with ST elevation myocardial ischemia. This report shows a patient who presented with chest pain and had an ECG compatible with Brugada. An ischemic workup was performed, and acute coronary syndrome was ruled out. He had a final diagnosis of BrS and was discharged home after the placement of an automatic defibrillator.
\end{abstract}

KEYWORDS: Ventricular tachycardia; Coronary artery disease; Brugada syndrome. 


\section{INTRODUCTION}

In 1953, a syndrome characterized by ST segment elevation in precordial derivations (V1 to V3) not related to ischemia, previous electrocardiographic alterations or obvious structural heart disease was initially described ${ }^{1}$. However, this syndrome was only recognized as a distinct clinical entity associated with a high risk of sudden cardiac death in 1992 and baptized as Brugada syndrome $(\mathrm{BrS})$, in honor of the authors who first described $\mathrm{it}^{2-4}$.

The distinction between these two entities can be difficult and challenging in patients who present with angina/ thoracic pain and typical Brugada alterations in the electrocardiogram (ECG), sometimes requiring other supplementary tests such as echocardiography, stress test or even coronary cineangiography for a definitive diagnosis.

This case describes a patient with chest pain of anginal characteristics and an electrocardiogram with a suggestive pattern of Brugada. After an extensive investigation, acute coronary syndrome was ruled out and the patient received a final diagnosis of Brugada syndrome, being discharged after implantable cardioverter defibrillator (ICD) implantation.

\section{CASE REPORT}

Male patient, 46 years old, dark-skinned, entered the emergency room with complaints of tight chest pain, with irradiation to the left upper limb, associated with dizziness, nausea and paresthesia in both upper limbs. The pain started when the patient was working in the field. According to the patient, the pain lasted for about two hours intermittently and there was no recovery with rest. He has also reported similar episodes in recent months.

According to the patient's wife, two weeks before the current presentation, she found her husband lying on the floor, disoriented, with noisy breathing and whitish secretion in his mouth. She also mentioned that her husband had strange movements in his legs and arms and was pale. This event lasted about a few seconds and the husband declared that he could only remember seeing the distressed woman by his side at the time. Patient denied chest pain, palpitations or other symptoms.

Previously healthy patient, denied diabetes, hypertension, previous hospital admissions, and use of medication. Family history of brother's sudden death at two months of age while breastfeeding.

Initial physical examination proved normal at his admission. His pressure was $120 / 75 \mathrm{mmHg}$, heart rate $66 \mathrm{bpm}$ and respiratory rate of 16 incursions per minute with oxygen saturation of $98 \%$ in ambient air.

Initially, an ECG was requested (Fig. 1) in which sinus rhythm, normal axis, right bundle branch block pattern, and evidence of ST segment elevation in precordial dedications from V1 to V3 with negative T wave in the same derivations can be verified. Subsequent electrocardiogram showed the same pattern with nonspecific ST segment changes in the lower wall (Fig. 2). Initial negative-ultrasensitive troponin in $0.1 \mathrm{ng} / \mathrm{mL}$. Other tests showed creatinine $0.8 \mathrm{mg} / \mathrm{dL}$, hemoglobin $14 \mathrm{mg} / \mathrm{dL}$, potassium $3.4 \mathrm{mEq} / \mathrm{L}$, sodium $140 \mathrm{mEq} / \mathrm{L}$.

Based on his history of chest pain with electrocardiographic alterations compatible with acute coronary syndrome and with negative troponin, ECG was requested and demonstrated an ejection fraction of 69\%, without segmental alterations and without valve alterations with normal aorta.

In order to exclude coronary syndrome, a computed tomography angiography of coronaries with normal results was requested. Ergometric test was performed to exclude exercise-induced arrhythmias or cardiac ischemia. The test was normal, with total energy expenditure of 10 METs, without arrhythmic or ischemic events in the ECG. Twentyfour-hour Holter normal, without arrhythmias.

Taking into account all the tests described above, acute coronary syndrome was excluded, and the diagnosis of Brugada syndrome was established. An electrophysiological study was performed and there was no induction of ventricular tachycardia or ventricular fibrillation with a protocol of two extrastimuli in the right ventricle. 
An ICD was implanted and the patient was discharged from home health. In the postdischarge follow-up, there were no episodes of chest pain, other symptoms or arrhythmias.

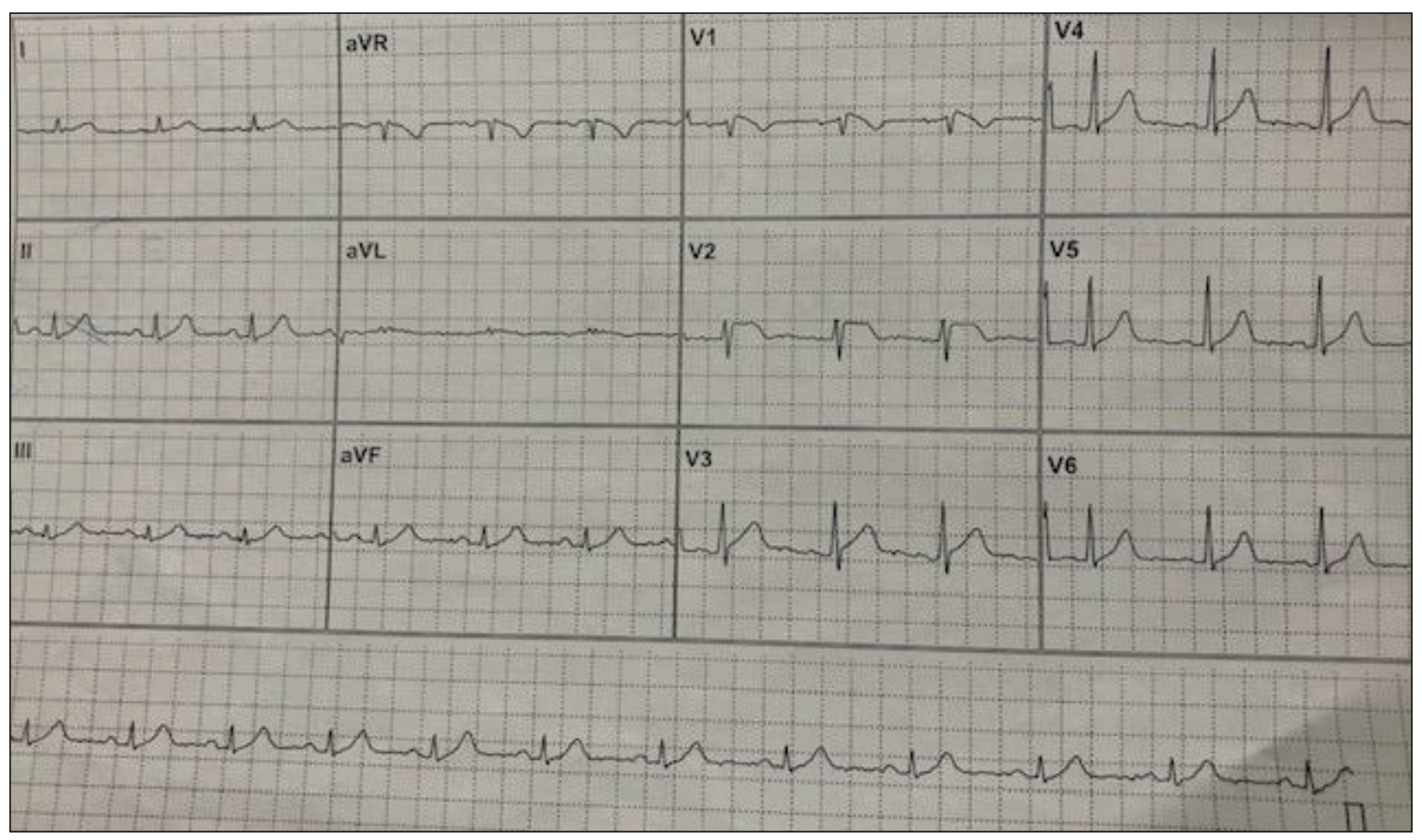

Figure 1. Initial electrocardiogram.

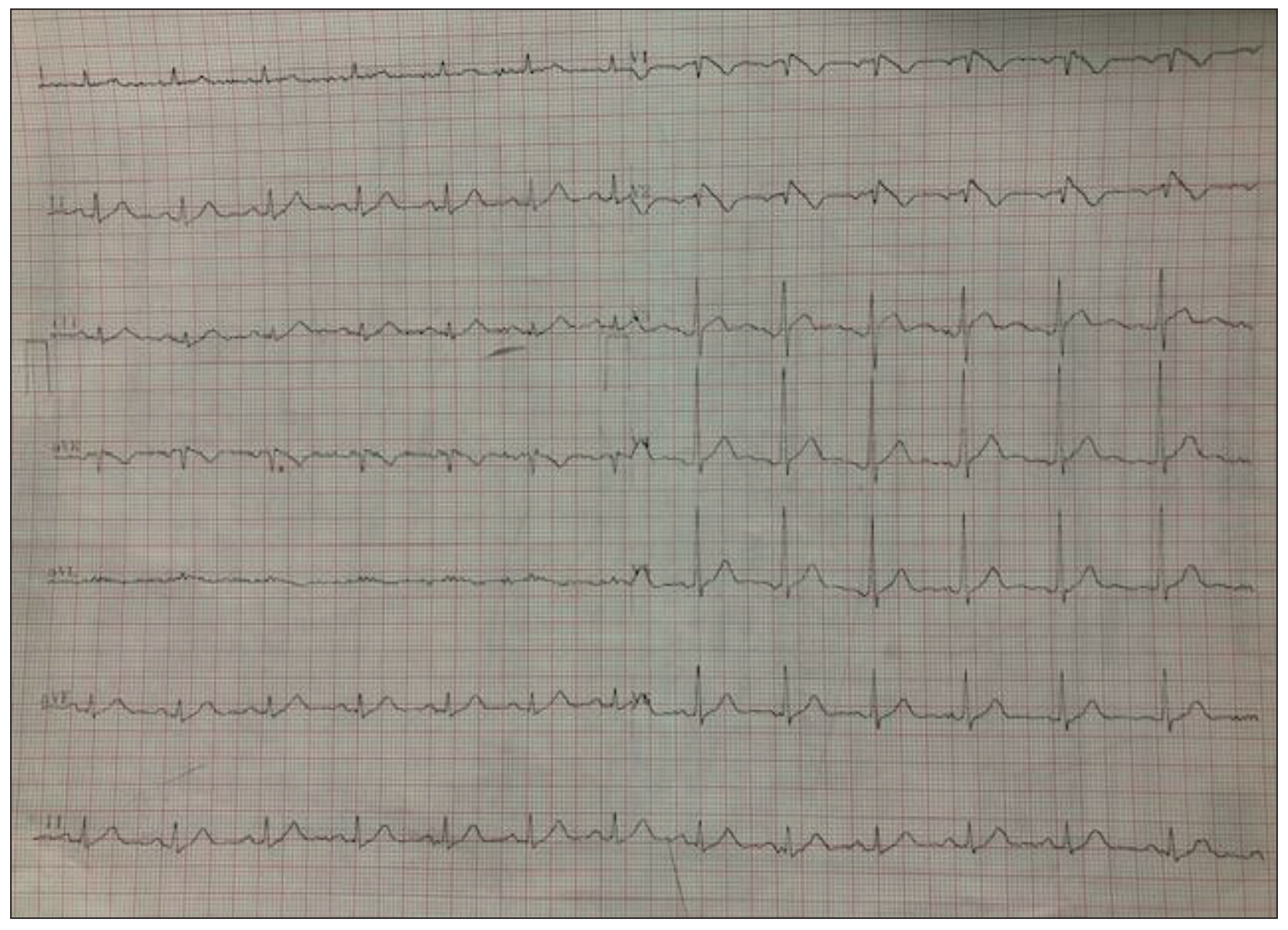

Figure 2. Follow-up electrocardiogram. 


\section{DISCUSSION}

The first electrocardiographic description of a ventricular tachycardia is attributed to Thomas Lewis, who described in 1909 a patient with shortness of breath, precordial pain and dizziness with 3 to 11 successive extrasystoles ${ }^{5}$.

Since then, systemic diseases, structural heart diseases such as right ventricular arrhythmogenic dysplasia and myocarditis in general, and especially ischemic heart diseases have been associated with ventricular arrhythmias, constituting their main cause today ${ }^{6}$.

Brugada syndrome (BrS), initially described as a new entity in 1992 by the Brugada brothers in Spain and later baptized in 1999 with their last name, is an autosomal dominant genetic disease with incomplete penetrance with an incidence that varies depending on the region. In general, the prevalence in adults is estimated at approximately $0.15 \%$ in Asian countries, including Japan, between 0.1 and $0.02 \%$ in Middle Eastern countries and less than $0.02 \%$ in Western countries ${ }^{7}$.

The $\mathrm{BrS}$ is an autosomal dominant channelopathy considered responsible for 4 to $12 \%$ of all sudden cardiac deaths and up to $20 \%$ of sudden cardiac deaths in normal hearts. This disease has a higher incidence in adult males. The symptoms occur mainly during rest or sleep 8 .

Its electrocardiographic alterations may be typical, with a right bundle branch block pattern and supra ST segment from $\mathrm{V} 1$ to $\mathrm{V} 3$ of more than $2 \mathrm{~mm}$ with $\mathrm{T}$ inversion with little or none isoelectric separation between both of them (type I pattern), have more subtle changes ( type 2 pattern) or even be unapparent (type 3 pattern) in the surface ECG, which can be observed when using sodium channel blockers such as ajmaline, which can unmask patients with hidden or borderline Brugada pattern ${ }^{9-11}$.

The most common gene associated with $\mathrm{BrS}$ is the SCN5A, present in approximately 20 to $25 \%$ of patients. More than 300 genetic mutations were found to be responsible for the deregulation in the function of sodium channels with slowing of cardiac conduction, causing the observed fatal arrhythmias ${ }^{12}$.

It is worth noting that some of these mutations in the SCN5A gene are also associated with other arrhythmic disorders such as long QT syndrome type 3 (LQT3) and sinoatrial node disease. Its distinction with the use of ajmaline is an important step that should be considered before starting treatment with class I drugs for patients diagnosed with LQT3, since there is a known overlap with $\mathrm{BrS}^{13}$.

Genetic research on specific mutations in patients diagnosed with Brugada syndrome as well as their family members currently has a level of evidence $\mathrm{I}^{14}$, although there are no conclusive studies yet showing that genetic research (with identification of mutations in the SCN5A gene) or family history of sudden death are risk factors for the prognosis of the disease ${ }^{15}$.

Treatment basically consists of primary prevention of fatal arrhythmias by means of ICD implantation ${ }^{16}$. In patients with ICDs who have episodes of ICD shock-terminated arrhythmias, drug therapy with quinidine can also be used to decrease the frequency of arrhythmias ${ }^{17}$.

Based on the electrophysiological mechanism of arrhythmias in patients with $\mathrm{BrS}$ characterized by delayed depolarization in the epicardial anterior portion of the right ventricular outflow tract, new therapeutic options, with ablation of these areas, show promising in the treatment of this condition ${ }^{18}$.

The initial presentation of the patient with typical thoracic pain, triggered by effort, and irradiation to the left upper limb with nausea made the diagnosis of coronary syndrome probable and, considering the high mortality of this condition, it was initially decided to perform a complete evaluation for exclusion of acute coronary syndrome.

After initial examinations that included laboratory evaluation, serial ECG, echocardiogram, computed tomography angiography of coronaries and ergometric test, acute coronary syndrome was excluded and the final diagnosis of Brugada syndrome was performed.

In the patient in question, the ergometric test was an important test, as ischemia can be observed with effort and also possible arrhythmias. Recent studies show that stress testing on patients with $\mathrm{BrS}$ type I helps to identify high-risk patients and provides a unique window of opportunity for early intervention ${ }^{19}$.

The patient remained asymptomatic and without events described during outpatient follow-up. Genetic mapping of the family was offered, but not performed.

Brugada syndrome is a potentially lethal disease, and although there is no treatment for the condition itself,ICD implantation definitely increases the survival of patients with this condition. Acute coronary syndrome should be part of the differential diagnosis and appropriate examinations should be performed in order to avoid false diagnosis of one condition or another. 


\section{REFERENCES}

1. Osher HL, Wolff L. Electrocardiographic pattern simulating acute myocardial injury: The American journal of the medical sciences. Am J Med Sci. 1953;226(5):541-5.

2. Brugada P, Brugada J. Right bundle branch block, persistent ST segment elevation and sudden cardiac death: A distinct clinical and electrocardiographic syndrome: a multicenter report. J Am Coll Cardiol. 1992;20(6):1391-6. https://doi.org/10.1016/07351097(92)90253-J

3. Brugada P, Brugada R, Antzelevitch C, Brugada J. The Brugada syndrome. Arch Mal Coeur Vaiss. 2005;98(2):115-22.

4. $\quad$ Alings M, Wilde AAM. "Brugada" syndrome: clinical data and suggested pathophysiological mechanism. Circulation. 1999;99(5):66673. https://doi.org/10.1161/01.CIR.99.5.666

5. McGovern B, Schoenfeld MH, Ruskin JN, Garan H, Yurchak PM. Ventricular tachycardia: historical perspective. Pacing Clin Electrophysiol. 1986;9(3):449-62. https://doi.org/10.1111/j.1540-8159.1986.tb04501.x

6. Srivathsan K, Ng DWC, Mookadam F. Ventricular tachycardia and ventricular fibrillation. Expert Rev Cardiovasc Ther. 2009;7(7):8019. https://doi.org/10.1586/erc.09.69

7. Kamakura S. Epidemiology of Brugada syndrome in Japan and rest of the world. J Arrhythm. 2013;29(2):52-5. https://doi. org/10.1016/j.joa.2013.01.004

8. García-Fuertes D, Villanueva-Fernández E, Crespín-Crespín M, Puchol A, Pachón M, Arias MA. Type 1 Brugada pattern unmasked during the recovery period of an exercise stress test. Arq Bras Cardiol. 2016;106(5):447-9. https://doi.org/10.5935/abc.20160071

9. Rolf S, Bruns H-J, Wichter T, Kirchhof P, Ribbing M, Wasmer K, et al. The ajmaline challenge in Brugada syndrome: diagnostic impact, safety, and recommended protocol. Eur Heart J. 2003;24(12):1104-12. https://doi.org/10.1016/S0195-668X(03)00195-7

10. Wilde AAM, Antzelevitch C, Borggrefe M, Brugada J, Brugada R, Brugada P, et al. Proposed diagnostic criteria for the Brugada syndrome: consensus report. Circulation. 2002;106(19):2514-9. https://doi.org/10.1161/01.CIR.0000034169.45752.4A

11. Antzelevitch C, Brugada P, Borggrefe M, Brugada J, Brugada R, Corrado D, et al. Brugada syndrome: report of the second consensus conference. Circulation. 2005;111(5):659-70. https://doi.org/10.1161/01.CIR.0000152479.54298.51

12. Juang J-MJ, Horie M. Genetics of Brugada syndrome. J Arrhythm. 2016;32(5):418-25. https://doi.org/10.1016/j.joa.2016.07.012

13. Hohmann S, Rudic B, Konrad T, Duncker D, König T, Tülümen E, et al. Systematic ajmaline challenge in patients with long QT 3 syndrome caused by the most common mutation: a multicentre study. EP Europace. 2016;19(10):1723-9. https://doi.org/10.1093/ europace/euw214

14. Priori SG, Wilde AAM, Horie M, Cho Y, Behr ER, Berul C, et al. HRS/EHRA/APHRS expert consensus statement on the diagnosis and management of patients with inherited primary arrhythmia syndromes. Heart Rhythm. 2013;10(12):1932-63. https://doi. org/10.1016/j.hrthm.2013.05.014

15. Brugada J, Campuzano O, Arbelo E, Sarquella-Brugada G, Brugada R. Present status of Brugada syndrome: JACC state-of-the-art review. J Am Coll Cardiol. 2018;72(9):1046-59. https://doi.org/10.1016/j.jacc.2018.06.037

16. Kusumoto FM, Bailey KR, Chaouki AS, Deshmukh AJ, Gautam S, Kim RJ, et al. Systematic review for the 2017 AHA/ACC/HRS guideline for management of patients with ventricular arrhythmias and the prevention of sudden cardiac death: a report of the American College of Cardiology/American Heart Association Task Force on Clinical Practice Guidelines and the Heart Rhythm Society. J Am Coll Cardiol. 2018;72(14):1653-76. Errata em: J Am Coll Cardiol. 2018;72(14):1756. https://doi.org/10.1016/j.jacc.2018.08.2133

17. Belhassen B, Glick A, Viskin S. Efficacy of quinidine in high-risk patients with Brugada syndrome. Circulation. 2004;110(13):1731-7. https://doi.org/10.1161/01.CIR.0000143159.30585.90

18. Nademanee K, Veerakul G, Chandanamattha P, Chaothawee L, Ariyachaipanich A, Jirasirirojanakorn K, et al. Prevention of ventricular fibrillation episodes in Brugada syndrome by catheter ablation over the anterior right ventricular outflow tract epicardium. Circulation. 2011;123(12):1270-9. https://doi.org/10.1161/CIRCULATIONAHA.110.972612

19. Subramanian M, Prabhu MA, Harikrishnan MS, Shekhar SS, Pai PG, Natarajan K. The utility of exercise testing in risk stratification of asymptomatic patients with type 1 Brugada pattern. J Cardiovasc Electrophysiol. 2017;28(6):677-83. https://doi.org/10.1111/ jce.13205 